\title{
BOOK REVIEW \\ OF BOGUSLAWSKA-TAFELSKA, M. 2016. ECOLINGUISTICS: COMMUNICATION PROCESSES AT THE SEAM OF LIFE. NEW YORK: PETER LANG
}

\author{
ZHOU WENJUAN
}

\section{Doctor Bogusławska-Tafelska as an already recognized Polish ecolinguist}

Doctor Marta Bogusławska-Tafelska, the editor of 'The Studies in Ecolinguistics' series of linguistic monographs at Cambridge Scholars Publishing', has authored several significant ecolinguistic monographs, including Towards an ecology of language, communication and the mind (2013), Towards the ecology of human communication (2015), Ecolinguistics: communication processes at the seam of life (2016), and Communication as a life process: beyond human cognition (2017).

Her research focus on ecolinguistics manifests itself mainly in the domain of cognition and communication in an endeavor of holistic and post-Newtonian paradigmatic framework of viewing communication basically as a life process, and Ecolinguistics: Communication Processes at the Seam of Life (2016) (Ecolinguistics hereafter) is one of the many monographs, which can reflect this core notion thoroughly.

Ecolinguistics covers seven chapters, plus Preface, References, and Appendix in length of 126 pages. The title of the book, according to the author, is inspired by Wlodzimierz Sedlak, the pioneer of quantum model of life (Bogusławska-Tafelska,

\footnotetext{
${ }^{1}$ For further information, see http://www.cambridgescholars.com/studies-in-ecolinguistics.
} 
2016: 42-43), and his canonical text Life is light (Bogusławska-Tafelska, 2016: 46). In the Preface part, the author calls for the shift of paradigm in language and communication ${ }^{2}$ studies of treating communication as a multidimensional process in the extended context of living system ${ }^{3}$ (Bogusławska-Tafelska, 2016: 8), under such circumstances as the junction of first-person and third-person pathways in scientific enterprises, the common paradigmatic ground that ecolinguists and transpersonalists share, and the new perspectives quantum physics and neurobiology may bring. Then the author offers the general unified and non-reductionist theoretical ground ${ }^{4}$ where this book stands, and the working definition of language/communication for the whole book. Then we will come to the gist of each chapter to figure out what makes communication a life process from the ecolinguistic perspective specifically.

\section{Gist of each chapter in Ecolinguistics}

\section{Chapter one: Ecolinguistics on the scientific map today}

In the introduction part of chapter one, the author states the central proposal of the book that ecolinguistics be perceived as a new linguistic paradigm, and then compares Halliday's functional grammar with Chomsky's transformative grammar from the perspective of product and process orientations. The author maintains that despite the more dynamic and creative linguistic view, the former holds (i.e. the focus on the functions of human audio-vocal communication), its material orientation and ignorance of the transpersonal dimensions of nonlocal systems within the Newtonian framework should be challenged greatly ${ }^{5}$. Accordingly, it is of great importance to recognize the transpersonal, local and non-local ${ }^{6}$ dimensions of communication, based on momentary meanings.

Section 1 of chapter one begins with the dichotomy of 'old linguistics' and 'new linguistics'. Based on a brief historical review of formal traditions of 'old linguis-

\footnotetext{
${ }^{2}$ The author uses 'language' and 'communication' interchangeably throughout the book.

${ }^{3}$ This notion of 'extension' is also echoed by Steffensen and Fill (2014), in which they maintain that the human ecology is extended by integrating value and meaning into ecological structures (Steffensen and Fill, 2014: 17). They define this notion as 'Extended Ecology Hypothesis'.

${ }^{4}$ Actually there is a common consesus among the current linguistic academia (e.g. Weigand, 2011) that linguistic paradigms need changing from reductionism to holism. Finke(2014) provides a focal account in this regard in the ecolinguistic domain. And Steffensen and Fill's plea for a unified langauge sceince (Steffensen and Fill, 2014) is also a case in point.

${ }^{5}$ Garner (2004) and Cowley (2014) offer a similar critical review of Halliday's ecolinguistic research orientation. And the Newtonian worldview model is also chanllenged by Zhou (2017) and Zhou and Huang (2017) in terms of dealing with the ecological crisis.

${ }^{6}$ The conception of non-locality of language (Bogusławska-Tafelska, 2013) is in line with Steffensen and Cowley's original pricinple of non-locality and non-localizability (Steffensen and Cowley, 2010).
} 
tics', the author summarizes them as adopting a 'materialistic, deterministic, and atomistic paradigm' (Bogusławska-Tafelska, 2016:14), and consequently concentrating on forms of language systems ${ }^{7}$. Then the author argues that if ecolinguistics turns to process orientation, such thinkers as Charles Pierce and Alfred Whitehead ${ }^{8}$ should be given enough attention due to their strong process orientation.

In section 2 of chapter one, the author reviews two influential figures in the history of ecolinguistics, Haugen and Halliday, regarding their central ecolinguistic tenets and basic limitations within the Newtonian paradigm. Then the author mentions two recent cases of newly ecolinguistic perspectives: the neo-Darwinian and cultural perspectives proposed by Puppel $(2008 ; 2009)$ (Bogusławska-Tafelska, 2016: 17).

Based on the common grounds that ecolinguistics and ecopsychology share, section 3 of chapter one illustrates several basic points for the proposal of this new unified post-Newtonian paradigm, especially the focus on human-nature relationships. Then the author foreshows the 'applicational strength of ecolinguistics' (Bogusławska-Tafelska, 2016: 19) in dealing with communicative and educational issues, ecological behaviours, ecological consciousness, and well-being in particular. This section ends with the author's redefinition of deep ecologist Naess's 'ecological self' and restatement of the notion of extension of human communication beyond the cognitive domain.

\section{Chapter two: From the speaker-hearer using language to the living system as embedded in relationships}

The introduction part of chapter two starts with the basic presumptions of language, linguistic meaning, and paradigmatic framework within Saussurean linguistics, and then continues a brief review of cognitivism, such influential figures as Chomsky, and the misinterpretations of the human mind ${ }^{10}$. Then the author summarizes the defects of mainstream cognitive linguistics concerning its atomistic thinking and computational process, to name just a few, which can largely find their roots in the atomistic, materialistic and deterministic Newtonian paradigm.

\footnotetext{
${ }^{7}$ The inclination of traditional linguisitics to forms and products of language systems has long been questioned by Harris (2013), and has approved by such linguistis as Love (2004) and Cowley (2016).

${ }^{8}$ There is an increasing consesus among current ecolinguists (e.g. Steffensen and Cowley, 2010; Cowley, 2016; Bogusławska-Tafelska, 2013, 2016) that Whitehead's works such as Science and the modern world (1926) and Process and reality (1978) do offer significant resources in advocating the notion of language/communication as a life process.

${ }^{9}$ This resembles Stibbe's ecosophy of living for wellbeing (Stibbe, 2015).

${ }^{10}$ Such misinterpretation of mind by mainstream cognitive linguistics can also be defined as 'the classic view of mind' (Love, 2004) or 'the mind myth' (Zhou, 2017).
} 
Section 1 of chapter two advocates a systems approach by drawing on Bertalanffy's general theory of systems ${ }^{11}$ instead of Halliday's systemic-functional grammar or mechanistic/linear models in the domains of western medical science. By doing so, the author highlights the transpersonal and emergent ${ }^{12}$ characteristics of human beings and language activity with three parties of human being/communicator, human communication, and communication models, in the form of energy and matter exchanges ${ }^{13}$. Fundamentally, human being is a living system, which continuously and emergently exchanges energy and matter (Bogusławska-Tafelska, 2016: 26); communication is an organismic process, and langauge is perceived as a holographic $\operatorname{sign}^{14}$ (Bogusławska-Tafelska, 2016: 27). This section finishes with the summary of human communication in its primariness of organic and procedual qualities and its secondariness of its cognitive and intellectual qualities ${ }^{15}$.

Section 2 of chapter two focuses on the further elaboration of human as a living sytem in the biopsychosocial model ${ }^{16}$ with the striking features of multimodality, comumunal structure, and key emergent properties.

Section 3 of chapter two presents the complementarist model of body-mind interaction. By 'complementarist', the author means the following three senses: the coexistence of human as a living system with other systems of life, the cohesion of different layers of living systems, the complementation of two opposing descriptions wihtin one organism ${ }^{17}$, and above all, the compossiblility of consciousness and matter.

\section{Chapter three: The possibility of a paradigmatic shift in present-day linguistics}

In the introduction part of chapter three, the author demonstrates two important realizations when it comes to current linguistic studies: neglect of the applications of the linguistic research, and thus a deeper paradigmatic rethinking.

${ }^{11}$ Similarly, Steffensen and Fill (2014) put emphasis on this theory. Cowley (2014) extends this systemic view by referring to one-system view.

${ }^{12}$ The emphasis on emergent characteristic coincides with van Lier's description of emergence from the perspective of language learning (van Lier, 2004).

${ }^{13}$ Chinese ecolinguist Li Guozheng also holds this notion of matter and energy flow alike in his canional text Ecolinguistic study of Chinese language (1991).

${ }^{14}$ Chinese linguist Qian Guanlian constructs the theory of language holograph in his profound monograph Theory of langauge holograph (2002).

${ }^{15}$ Love puts forward analogical notions of first-order activity and second-order cognition (Love, 2004). Cowley extends that into first-order languaging and second-order language (e.g. Cowley, 2014; 2016).

${ }^{16}$ This model matches Cowley's redefintiion of bio-ecology as the domain of plant-animalhuman-culture formations (Cowley, 2014).

${ }^{17}$ This idea is very similar to ecological movements of langauge proposed by Li Guozheng (1991), in which seven types of ecological movement of language are each characterized by two counterpoints: "opposition and complementation", "assimilation and variation", "generalization and specialization", "intension and attenuation", "extension and prevention", "permeation and coordination", and "drifting and selecting". 
Section 1 of chapter three offers a clear picture of significant ecolinguistic contributions in Poland, including university master degree programs, domestic conferences, and collective monographs, besides such ecolinguists as Tudor (2001) and Goatly (2001) (Bogusławska-Tafelska, 2016: 34-35). Then the author suggests that linguists can refer to non-linugistic fields such as consciounsess studies, holoism approaches, quantum physics to start interdisciplinary research to cope with the dominant Newtonian model and its residual influences thereabouts.

Section 2 of chapter three traces the root of the overwhelming materialistreductionist paradigm, the Newtonian model of the world, back to, first and foremost, Plato, Aristotle, and Descartes, and then to American behaviorism, and then, in turn, to structuralism. The author points out 'Structuralism, with its focus on overt linguistic behavior, forms and structures was inspired by behaviorism in psychology' (Bogusławska-Tafelska, 2016: 38). Basically, 'Cartesian dualism not only equated the human body with an atomistic, materialistic machine, but also initiated atomisitc and mechanic treatment of mind' (Bogusławska-Tafelska, 2016: 39). One corollary of this scientific thinking, accordingly, is that communication is treated as a separate process.

\section{Chapter four: Life is light: quantum unfolding of reality}

The introduction part of chapter four enters on the likelihood of the multidimensionality of life process granted by quantum theory and holism methodology on the account of biological study of living matter and physical study of non-living matter. Then the author mentions two pathways concerning the functions of human mind research: human mental functions in the light of quantum thinking and the meeting function of cytoskeleton between matter and non-matter.

The focuses of section 1 of chapter four are Sedlak's biography, his theory of the 'seam of life', and the profound influences of his theory on the development of natural sciences and ecolinguistics. This theory of 'life is light' comes down to, theoretically, the quantum continuity from biological to nonmaterial dimensions of life phenomena, conceptually, the extension from cognitive contexts to noncognitive ones, and paradigmatically, the breakthrough from the chemo-biological paradigm to the multidisciplinary one of integrating bioelectrics, and phenomenological mysticism.

Section 2 of chapter four talks about Penrose's microstructure (e.g. eukaryotic cells ${ }^{18}$ ) theory and its feasibility in the newly proposed ecolinguistic model. In Penrose's terms, deep intracellular processes of human mind make it possible for matter to meet non-matter, which can result from activeness of mind. The author thinks that

\footnotetext{
${ }^{18}$ Similarly, Cowley and Zhou (2017) hold similar opinions concerning the microstructure of life forms.
} 
Penrose's hypothesis is significant in that it offers solid philosophical and theoretical justifications of interpreting communication as a non-computationa ${ }^{19}{ }^{19}$ life process occurring at various layers of the living system.

Section 3 of chapter four goes on to elaborate the quantum essence of reality that human living is exposed to by consulting quantum field theory. The author concludes in this section that 'we are quantum creatures embedded within a quantum field of life' (Bogusławska-Tafelska, 2016: 50), and 'all living and non-living systems are quantum classical systems' (ibid).

When it comes to quantum field theory itself in section 4 of chapter four, the author first explains the relevant concepts of 'field' and 'space', and then conceives the holistic, transorganismic, and nondual mechanism that the newly ecolinguistic theory can rely on.

In section 4 of chapter four, the author proposes a systemic theory of ecolinguistics as the 'holographic' sign, which constitutes communication modalities in living systems, sign as a hologram, and organic creativity. To begin with, communication modalities integrate cognitive and non-cognitive communication mechanisms with diverse types of communicational terrains with processes and relations. The nonlocal/quantum cell-to-cell communication, as the author underlines, remains inclusive of chemical and classical communication. In a word, 'communicative processes can be found on a complete range of scales' ${ }^{20}$ (Bogusławska-Tafelska, 2016: 53). Then communication sign, as a positive response to linguistic sign in the sense of the mainstream linguistics, can be understood metaphorically as 'an abstract ${ }^{21}$, multidimensional effect' (Bogusławska-Tafelska, 2016: 54) ascribed to the communicator in the extended communicative context. Organic creativity ${ }^{22}$ to this effect can interact with reality in a set of relational mechanisms, where working memory systems can play a leading role in this aspect.

\section{Chapter five: In search of a new methodology}

The introduction part of chapter five appeals to a new approach to ecolinguistics, and above all, a novel theoretical basis for this approach.

Section 1 of chapter five evaluates the third-person and sense-based western science, and then introduces first-person, non-local, non-casual, and transpersonal dimensions of phenomenological insights into scientific methods.

\footnotetext{
${ }^{19}$ Cowley (2011) also challenges the computational view of cognition in current studies.

${ }^{20}$ Cowley (2016) states the parallel definition of language as multi-scalar process, as enlightened by Love (2004).

${ }^{21}$ The reviewer thinks the abtract quality of communication sign as a hologram is not clearly formulated here. For such a quality may contradict itself with the author's standpoint of opposing the traditional paradigm of language form and products.

${ }^{22}$ The idea of creativity in the domain of cognitive linguistics and ecolinguistics is highly valued by such ecolinguistics as Garner (2014), Cowley (2011; 2014), and Kravcheko (2016).
} 
Section 2 of chapter five stresses the emergentist position of brain functions rooted in neurophenomenology. This emergentist position, accordingly, can attach complementary significance to the new ecolinguistic paradigm in communication studies: 'to combine materialistically-oriented research of forms and structures with the first-person insightful phenomenology touching the personal, organically creative experience' (Bogusławska-Tafelska, 2016: 60).

In section 3 of chapter five, the author specifies the key premises the ecolinguistic methodology can follow, that is, the affirmation of first-person/inner experience in linguistic research and introduction of first-person perspective into communication studies. In so doing, one, as the author suggests, can refer to Roger Bacon, Franz Brentano, and Asia Buddhism ${ }^{23}$.

Section 4 of chapter five lists four methodological principles: the local research orientation, the naturalistic ${ }^{24}$ approach, the formative character, and last but not least, ecolinguistic awareness of understanding and inner knowing for the researcher.

The author exhibits an example of ecolinguistic analysis of linguistic meanings, based on student questionnaires, in terms of students and teachers' profiles in quality control, at the Institute of Neophilology of University of Warmia and Mazury. Then the author analyses the potential sources for problems with communication and ecolinguistic and psycholinguistic awareness, as well as the underlying meanings. The author concludes that the construction of meaning can be comprehended as a multilayered life process, independent of formal linguistic data from the questionnaires.

\section{Chapter six: Ecolinguistic applications: an extended educational paradigm}

The introduction part of chapter six reemphasizes the dedication of this book to paradigm shift in the educational context, for example, Polish educational systems, to cope with common communicative problems existing in youngsters.

Section 2 of chapter six looks back on the author's previous research with respect to participants of educational process (i.e. students and academic teachers), and mindful education in Poland, that is, transpersonal and transformative education. This section ends with what makes 'holism of treatment'(Bogusławska-Tafelska, 2016: 78), including interconnectedness between general educational aims in the macro-level, and self- awareness skills in the micro-level; conception and application of quantum layer of life; new transpersonal models of communication; and new roles endowed to students and teachers.

In section 3 of chapter 6 , the author comes up with the future direction of the current education towards 'a culture of consciousness' by taking in transpersonal

\footnotetext{
${ }^{23}$ Bang et al. (2007) show similarly affirmative attitudes towards the philosophical values of Buddhism in this regard.

${ }^{24}$ This naturalistic inclination is analogous to Steffensen and Fill's proposal of a naturalized view on language (Steffensen and Fill, 2014).
} 
psychology. Then the author provides another pilot research of young people on their conceptualization of such terms as 'mindfulness', 'meditation' and 'spirituality'. In conclusion, the author holds that the conceptual-terminological constructs should be dealt with cautiously to account for the new direction clearly.

\section{Chapter seven: Linguistic labeling ${ }^{25}$ as a feedback process of bringing the named into being-the ecolinguistic perspective}

Based on the notion that 'linguistic labeling affects a communicator's experience', the author demonstrates two scientific thinking models: cognitivist and biopsychosocial ones.

Section 1 of chapter seven discusses the cognitive frame theory of human mind in such domains as medicine and health program. The frame analysis of communicative intention is involved in this aspect in the form of medical consultation. Then author draws the conclusion that this psycholinguistic modal can shed lights on viewing language process as the primary intervention modality.

In the section 2 of chapter seven, the author suggests shifting from the above psycholinguistic model to the philosophical-epistemological-methodological one due to the inefficiency the former holds in terms of its Newtonian classical thinking pattern.

Section 3 of chapter seven proposes the concept of 'mind-body as the entangled whole' (Bogusławska-Tafelska, 2016: 78) on the description of Generalized Quantum Theory, with the following basic assumption that mental and material qualities can influence each other, and meanwhile such complementarities can be defined as non-commuting phenomena (Bogusławska-Tafelska, 2016: 106-107).

In the last section of chapter seven, the author sums up the general proposal for the new ecolinguistic paradigm by redefining a cluster of concepts like 'reality' and 'first-person, inner communicative process' (Bogusławska-Tafelska, 2016: 108109), and reiterates the significance this new first-person and non-Newtonian paradigm can inspire for rethinking the interconnectedness of life.

\section{Boguslawska-Tafelska's central ecolinguistic tenets}

\subsection{Boguslawska-Tafelska's view of language/communication and mind}

Boguslawska-Tafelska adopts a strong orientation of treating langauge/communication as a life process out of the paradigmatic and theoretical limitations of main-

\footnotetext{
${ }^{25}$ The reviewer thinks that it would be better for the author to define explicitly what linguistic labeling means, the specific relevant examples, and what corelation of linguistic labelling and the ecolinguistic propasal may exist in this book at the very beginning of this chapter.
} 
stream cognitive linguistics, typically presented in Chomsky and Halliday's views of langauge and communication. To begin with, the author maintains that 'However dynamic Halliday's theory of grammar is, as long as it is formulated within the Newtonian paradigmatic framwwork, will refer to the technology of human cognitive communication and will have important theretical as well as research limitations' (Bogusławska-Tafelska, 2016: 13). Specifically, what Halliday's systemic grammar rests on 'is not a systems theory as built by Bertalanffy (1968), in which life systems occupy the whole spectrum' (Bogusławska-Tafelska, 2016: 12). Similarly, she points out radically that from the ecolinguistic perspective, 'The communicator in Chomsky's proposals remains generally and ideally profiled. $\mathrm{He} / \mathrm{she}$ is functioning with an ideal language environment' (Bogusławska-Tafelska, 2016: 23).

Given the basic challenge to the scientific view of human mind ((BogusławskaTafelska, 2016: 24), the author labels human mind as 'a cognitive tool for adaptation and the organismic navigation' (Bogusławska-Tafelska, 2016: 102) in the complementarist model of mind-body as a whole.

\subsection{Boguslawska-Tafelska's view of ecolinguistics}

Quite different from other orientations of ecolinguistics, the author locates ecolinguistics as a new linguistic paradigm or a new pathway in linguistics, i.e. the ecolinguistics of human communication, as follows: 'ecolinguistics will one day go beyond cognitive and social contexts to the contexts of life process in the multidimensional sense' (Bogusławska-Tafelska, 2016: 16). Besides, the so-called 'applicational attribute' of ecolinguistics is much emphasized in the latter part of the book (Bogusławska-Tafelska, 2016: 63), especially in the educational context. The author puts it like this:

Our ecolinguistic proposals for education include creating teacher training workshops and seminars in which primary, secondary and higher educations teachers could learn the basic concepts of quantum physics, theories of quantum brain/mind dynamics, models of transpersonal, nonlocal and communication/relations, the ecolinguistic paradigm in contemporary language and communication studies, the system theory of life organization, among other principles' (Bogusławska-Tafelska, 2016: 77).

\section{Implications for ecolinguistics}

The major contribution of this book to ecolinguistic literature is that it offers a new ecolinguistic paradigm in language and cognition studies. By doing so, it introduces not only such interdisciplinary studies as transpersonal psychology and generalized quantum theory into the current linguistic models, but also challenges 
Newtonian worldview model at the paradigmatic and philosophical root of mainstream communication studies under the influences of Saussure, Halliday and Chomsky.

The novel ideas which have not been discussed by those previous publications are as follows: (1) the conceptualization of transpersonal and quantum dimensions of language/communication as a life process; (2) the comparison between mainstream cognitive linguistics and ecolinguistics in terms of basic conceptions of language/communication, and human mind; and (3) the construction of a new ecolinguistic proposal of viewing language and communication as a holographic sign in the complementarist model of all living systems.

\section{Conclusion}

In conclusion, the author's effort to conceptualize a life process framework of ecolinguistics that connects material/cognitive aspects of language/communication with those of quantum/nonlocal ones will exert a profound influence on the future horizons of ecolinguistics with the increasing consensus of viewing the discipline as a life science in achieving ecological harmony.

\section{Funding}

This article was sponsored by State-Sponsored Scholarship Program for Special Needs organized by Chinese Scholarship Council [grant number [2015(5103)], file number 201508155037].

\section{References}

Bang, J.C., Døør, J., 2007. In: Steffensen, S.V., Nash, J. (Eds.), Language, ecology, and society: a dialectical approach. New York/London: Continuum.

Bogusławska-Tafelska, M., 2013. Towards an ecology of language, communication and the mind. Frankfurt am Main: Peter Lang Verlag.

Bogusławska-Tafelska, M., 2015. Towards the ecology of human communication. Newcastle upon Tyne: Cambridge Scholars Publishing.

Bogusławska-Tafelska, M., 2016. Ecolinguistics: communication processes at the seam of life. New York: Peter Lang Verlag.

Bogusławska-Tafelska, M., 2017. Communication as a life process: beyond human cognition. Newcastle upon Tyne: Cambridge Scholars Publishing.

Cowley, S.J., 2011. "Distributed language". In: Cowley, S.J. (ed.), Distributed language. Amsterdam/Philadelphia: John Benjamins. 185-210.

Cowley, S., 2014. "Bio-ecology and language: a necessary unity". Lang. Sciences 41. 60-70. http://dx. doi.org/10.1016/j.langsci.2013.08.007. 
Cowley, S.J., 2016. "Changing the idea of language: Nigel Love's perspective". Language Sciences 61. 43-55. http://dx.doi.org/10.1016/j.langsci.2016.09.008.

Cowley, S. (斯蒂芬・考利), Zhou, Wenjuan (周文娟), 2017. 生态语言学视域 : 语言与生物生态的必 然统一(“An ecolinguistic terrain: language and the bio-ecology”). Journal Poyang Lake 2. 5-21.

Finke, P., 2014. "The ecology of science and its consequences for the ecology of language". Language Sciences 41. 71-82. http://dx.doi.org/10.1016/j.langsci.2013.08. 008.

Garner, M., 2014. "Language rules and language ecology". Language Sciences. 41. 111-121. http://dx. doi.org/10.1016/j.langsci.2013.08.012.

Harris, R., 2013. "The role of the language myth in the Western culture". In: Harris, R. (ed.). The language myth in the Western culture. London/New York: Routledge/Taylor and Francis Group. 1-24.

Kravchenko, A., 2016. "Two views on language ecology and ecolinguistics". Language Sciences 54. 102-113. http://dx.doi.org/10.1016/j.langsci.2015.12.002.

Li, Guozheng (李国正), 1991. 生态汉语学(Ecolinguistic study of Chinese language). Changchun: Jilin Education Press.

Love, N., 2004. "Cognition and the language myth". Language Sciences 26 (6). 525-544. http://dx. doi.org/10.1016/j.langsci.2004.09.003.

Puppel, S. 2008. "Communicology: remarks on the reemergence of a paradigm in communication studies”. In: Puppel, S. and M. Bogusławska-Tafelska (eds.). New pathways in linguistics 2008. Olsztyn: Uniwersytet Warmińsko-Mazurski. 11-22.

Puppel, S. 2009. "Remarks on the sustainability of natural languages in the cultural-institutional perspective”. In: Puppel, S. and M. Bogusławska-Tafelska (eds.). New pathways in linguistics 2009. Olsztyn: Uniwersytet Warmińsko-Mazurski. 275-286.

Qian Guanlian (钱冠连), 2002. 语言全息论 (Theory of langauge holograph). Beijing: The Commercial Press.

Steffensen, S.V. and S.J. Cowley. 2010. "Signifying bodies and health : a non-local aftermath". In: Steffensen, S.V. and S.J. Cowley (eds.). Signifying bodies: biosemiosis, interaction and health. Braga: The Faculty of Philosophy of Braga, Portuguese Catholic University. 331-355.

Steffensen, S.V. and A. Fill. 2014. "Ecolinguistics: The state of the art and future horizons". Language Sciences 41. 6-25. http://dx.doi.org/10.1016/j.langsci.2013.08. 003.

Stibbe, A. 2015. Ecolinguistics: language, ecology and the stories we live by. London: Routledge.

van Lier, L. 2004. The ecology and semiotics of language learning. A sociocultural perspective. Dordrecht: Kluwer.

Weigand, E. 2011. "Paradigm changes in linguistics: from reductionism to holism". Language Sciences 33. 544-549.

Whitehead, A. 1926. Science and the modern world. Cambridge: Cambridge University Press.

Whitehead, A. 1978. Process and reality. New York: Free Press.

Zhou, W. 2017. "Ecolinguistics: toward a new harmony". Language. Sciences 62. 124-138. doi.org/10. 1016/j.langsci.2017.04.004.

Zhou, W. and G. Huan. 2017. "Chinese ecological discourse: a Confucian-Daoist inquiry”. Journal of Multicultural Discourses 4. 264-281. 